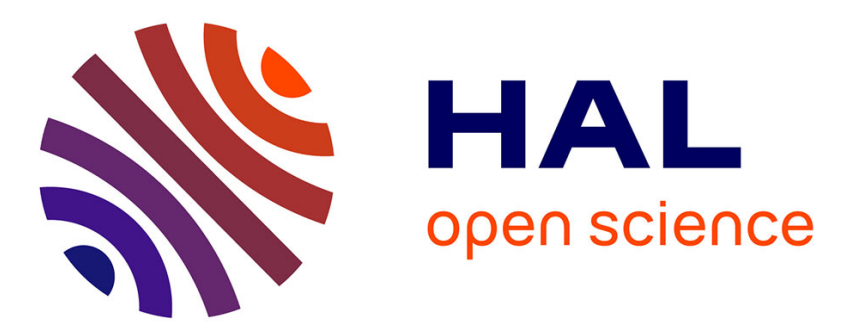

\title{
Association between annoyance and individuals' values of nitrogen dioxide in a European setting.
}

Bénédicte Jacquemin, Jordi Sunyer, Bertil Forsberg, Inmaculada Aguilera, David Briggs, Thomas Götschi, Joachim Heinrich, Kjell Torén, Danielle Vienneau, Nino Künzli

\section{To cite this version:}

Bénédicte Jacquemin, Jordi Sunyer, Bertil Forsberg, Inmaculada Aguilera, David Briggs, et al.. Association between annoyance and individuals' values of nitrogen dioxide in a European setting.. J Epidemiol Community Health, 2008, 62 (5), pp.e12. inserm-00288103

\section{HAL Id: inserm-00288103 https://www.hal.inserm.fr/inserm-00288103}

Submitted on 17 Jun 2008

HAL is a multi-disciplinary open access archive for the deposit and dissemination of scientific research documents, whether they are published or not. The documents may come from teaching and research institutions in France or abroad, or from public or private research centers.
L'archive ouverte pluridisciplinaire HAL, est destinée au dépôt et à la diffusion de documents scientifiques de niveau recherche, publiés ou non, émanant des établissements d'enseignement et de recherche français ou étrangers, des laboratoires publics ou privés. 


\section{Association between annoyance and individuals' values of nitrogen dioxide in a European setting}

B Jacquemin, J Sunyer, B Forsberg, I Aguilera, D Briggs, T Götschi, J Heinrich, K Torén, D Vienneau and N Künzli

J. Epidemiol. Community Health 2008;62;12doi:10.1136/jech.2007.066340

Updated information and services can be found at:

http://jech.bmj.com/cgi/content/full/62/5/e12

These include:

References This article cites 19 articles, 8 of which can be accessed free at: http://jech.bmj.com/cgi/content/full/62/5/e12\#BIBL

Rapid responses You can respond to this article at: http://jech.bmj.com/cgi/eletter-submit/62/5/e12

Email alerting Receive free email alerts when new articles cite this article - sign up in the box at service the top right corner of the article

Notes

To order reprints of this article go to:

http://journals.bmj.com/cgi/reprintform

To subscribe to Journal of Epidemiology and Community Health go to:

http://journals.bmj.com/subscriptions/ 


\title{
Association between annoyance and individuals' values of nitrogen dioxide in a European setting
}

\author{
B Jacquemin, ${ }^{1}$ J Sunyer, ${ }^{1,2}$ B Forsberg, ${ }^{3}$ I Aguilera, ${ }^{1}$ D Briggs, ${ }^{4}$ T Götschi, ${ }^{5} \mathrm{~J}$ Heinrich, ${ }^{6}$ \\ K Torén, ${ }^{7}$ D Vienneau, ${ }^{4}$ N Künzli ${ }^{1,5,8}$
}

${ }^{1}$ Municipal Institute of Medical

Research, Barcelona, Spain;

${ }^{2}$ Universitat Pompeu Fabra,

Barcelona, Spain; ${ }^{3}$ Umeå

University, Umeå, Sweden;

${ }^{4}$ Imperial College, London, UK;

${ }^{5}$ University of Southern

California, Los Angeles,

California, USA; ${ }^{6}$ GSF Institute

of Epidemiology, Munich,

Germany; ${ }^{7}$ Sahlgrenska

University Hospital, Göteborg,

Sweden; ${ }^{8}$ Institució Catalana de

Recerca i Estudis Avançats,

Barcelona, Spain

Correspondence to:

B Jacquemin, Inserm U780,

Epidémiologie et Biostatistique,

16, avenue Paul Vaillant

Couturier, 94807 Villejuif Cedex,

France; benedicte.jacquemin@

inserm.fr

Accepted 18 November 2007

\section{ABSTRACT}

Introduction: Annoyance caused by air pollution has been proposed as an indicator of exposure to air pollution. The aim of this study was to assess the geographical homogeneity of the relationship between annoyance and modelled home-based nitrogen dioxide $\left(\mathrm{NO}_{2}\right)$ measurements.

Methods: The European Community Respiratory Health Survey II was conducted in 2000-1, in 25 European centres in 12 countries. This analysis included 4753 subjects (from 37 in Tartu, Estonia, to 532 in Antwerp, Belgium) who answered the annoyance question and with available outdoor residential $\mathrm{NO}_{2}$ (4399 modelled and 354 measured) including 20 cities from 10 countries. Annoyance as a result of air pollution was self-reported on an 11-point scale (0, no disturbance at all; 10 , intolerable disturbance). Demographic and socioeconomic factors, smoking status and the presence of respiratory symptoms or disease were measured through a standard questionnaire. Negative binomial regression was used.

Results: The median $\mathrm{NO}_{2}$ concentration was $27 \mu \mathrm{g} \cdot \mathrm{m}^{-3}$ (from 10 in Umeå, Sweden, to 57 in Barcelona, Spain). The mean of annoyance was 2.5 (from 0.7 in Reykjavik, Iceland, to 4.4 in Huelva, Spain). $\mathrm{NO}_{2}$ was associated with annoyance (ratio of the mean score 1.26 per $10 \mu \mathrm{g} \cdot \mathrm{m}^{-3}, 95 \% \mathrm{Cl} 1.19$ to 1.34$)$. The association between $\mathrm{NO}_{2}$ and annoyance was heterogeneous among cities ( $p$ for heterogeneity $<0.001$ ).

Conclusions: Annoyance is associated with home outdoor air pollution but with a different strength by city. This indicates that annoyance is not a valid surrogate for air pollution exposure. Nevertheless, it may be a useful measure of perceived ambient air quality and could be considered a complementary tool for health surveillance.

The assessment of individuals' exposure to trafficrelated air pollution is complicated. Personal or home outdoor measurements are not easily feasible in large epidemiological studies and tend to be very expensive. Modelling presents an alternative; but adequate information is not always available on source emissions or from environmental measurements. ${ }^{1}$ It has been suggested that annoyance caused by air pollution reported through a questionnaire could be used as an indicator of exposure to air pollution. ${ }^{2}{ }^{3}$ Several studies have shown a moderate to good association between central levels of air pollution and annoyance but they also concluded that personal characteristics were stronger determinants than the actual levels of air pollution..$^{2-8}$ Few studies have assessed the association between nitrogen dioxide $\left(\mathrm{NO}_{2}\right)$ exposure at the individual level and annoyance caused by air pollution. $\mathrm{NO}_{2}$ is widely used as a marker of exposure to traffic-related pollutants. Compared with other pollutants of interest, such as particulate matter of various sizes, it is far easier to measure $\mathrm{NO}_{2}$ at many locations throughout a city. Such measurements combined with modelling approaches are frequently used to characterise spatial gradients of traffic-related pollution. Oglesby et $a^{\beta}$ suggested that annoyance could not replace home-based measurements, as annoyance was strongly influenced by personal factors and they also suggested that even adjusting for all the personal determinants would not be enough as they found interactions between $\mathrm{NO}_{2}$ and individuals' variables. Rotko et $a l^{5}$ did not find an association between home outdoor $\mathrm{NO}_{2}$ and annoyance caused by air pollution while at home when doing the analysis at an individual level; they only found an association at the population level. In a previous study, we showed the determinants of annoyance in the European Community Respiratory Health Survey II (ECRHSII) population and we found a moderate association between annoyance and central measurements of particulate matter up to 2.5 microns in diameter and its sulphur content, although heterogeneous across centres. ${ }^{4}$ Annoyance is assessed for the local environment around the house, which is not captured by centrally measured background pollutants. At that time home outdoor measurements of air pollution were available in a subgroup only. We have now linked modelled $\mathrm{NO}_{2}$ home outdoor concentrations for the residence of the majority of subjects. This allows us to assess the association between air pollution and annoyance caused by air pollution, at the individual level in a larger population.

The objective of this study was to assess the association between reported annoyance caused by air pollution and home outdoor levels of $\mathrm{NO}_{2}$ in 20 cities from 10 countries and investigate the geographical homogeneity thereof.

\section{MATERIALS AND METHODS Study population}

The European Community Respiratory Health Survey was carried out in 28 urban centres in 11 European countries. It was first conducted in 19913 and repeated in 1999-2001. Centres were chosen on the basis of pre-existing administration boundaries, their size and the availability of sampling frames. Subjects were randomly selected from the populations aged 20-44 years in 1991-3. A subsample of symptomatic subjects was also recruited. The details of this project study are described elsewhere. ${ }^{9} 10$ 
Table 1 Description of outdoor $\mathrm{NO}_{2}$ (median and interquantile range) and description of annoyance (mean and percentage of highly annoyed), per city

\begin{tabular}{|c|c|c|c|c|c|c|c|}
\hline \multirow[b]{2}{*}{ Centre* } & \multicolumn{2}{|l|}{$\mathbf{N}$} & \multicolumn{3}{|c|}{$\mathrm{NO}_{2} \dagger$ in percentiles } & \multicolumn{2}{|c|}{ Annoyance } \\
\hline & $\begin{array}{l}\text { With modelled } \\
\mathrm{NO}_{2}\end{array}$ & $\begin{array}{l}\text { With measured } \\
\mathrm{NO}_{2}\end{array}$ & p25 & p50 & p75 & Mean & $\% \geqslant 6$ \\
\hline Reykjavik (IC) & 0 & 82 & 7.30 & 12.25 & 19.20 & 0.70 & 1 \\
\hline Upssala (SW) & 487 & 0 & 11.27 & 15.45 & 19.75 & 1.04 & 5 \\
\hline Tartu (ES) & 0 & 37 & 19.30 & 22.20 & 26.20 & 2.54 & 11 \\
\hline Goteborg (SW) & 318 & 0 & 23.41 & 26.67 & 28.74 & 1.04 & 4 \\
\hline Ipswich (UK) & 232 & 12 & 24.90 & 26.10 & 28.00 & 2.95 & 23 \\
\hline Antwerp (BE) & 532 & 0 & 22.99 & 27.83 & 32.93 & 3.36 & 24 \\
\hline Erfurt (GE) & 83 & 0 & 19.61 & 24.48 & 25.84 & 2.90 & 18 \\
\hline Paris (FR) & 424 & 0 & 49.05 & 50.46 & 52.57 & 3.34 & 25 \\
\hline Basel (SZ) & 0 & 88 & 29.23 & 34.35 & 38.75 & 3.57 & 30 \\
\hline Grenoble (FR) & 382 & 0 & 25.41 & 30.80 & 31.45 & 2.69 & 16 \\
\hline Galdakao (SP) & 359 & 0 & 19.89 & 25.50 & 33.02 & 2.61 & 16 \\
\hline Barcelona (SP) & 255 & 1 & 53.45 & 57.32 & 59.19 & 3.61 & 25 \\
\hline Albacete (SP) & 140 & 4 & 28.32 & 29.75 & 31.81 & 3.35 & 24 \\
\hline Huelva (SP) & 204 & 0 & 29.68 & 33.42 & 33.70 & 4.38 & 40 \\
\hline Total & 4399 & 354 & 19.89 & 27.10 & 32.93 & 2.48 & 16.73 \\
\hline
\end{tabular}

$\mathrm{NO}_{2}$, nitrogen dioxide; BE, Belgium; ES, Estonia; FR, France; GE, Germany; IC, Iceland; IT, Italy; SP, Spain; SW, Sweden; SZ, Switzerland; UK, United Kingdom. ${ }^{*}$ Cities are ordered from north to south.

†Including 4399 modelled plus 354 measured home outdoor $\mathrm{NO}_{2}$ levels.

This analysis was based on the second survey, including all the subjects from the random samples with modelled home outdoor $\mathrm{NO}_{2}$ who had answered the annoyance question. Less than $3 \%$ of the subjects included in the analysis (141 subjects out of 4898) did not respond to the annoyance question. When the modelled $\mathrm{NO}_{2}$ was not available, home outdoor measurements were used if obtained. A total of 4753 (4399 with modelled $\mathrm{NO}_{2}$ and 354 with measured home outdoor $\mathrm{NO}_{2}$ ) subjects in 20 cities in 10 countries were included. Sample size varied by centre from 37 in Tartu (Estonia) to 532 in Antwerp (Belgium). Ethical approval was obtained for each centre from the appropriate institutional or regional ethics committee, and written consent was obtained from each participant.

\section{Description of variables}

Annoyance caused by air pollution was self-reported on an 11point scale ( 0 , no disturbance at all; 10 , intolerable disturbance) through the following question: "How much are you annoyed by outdoor air pollution (from traffic, industry, etc) if you keep the windows open?". The other variables used in this analysis were sex, age, night shortness of breath, chronic phlegm, ever rhinitis, socioeconomic status (based on occupation), smoking (never, ex, current) and exposure to environmental tobacco smoke. Self-reported traffic was also associated with annoyance but it was not used in this analysis because it is closely related to $\mathrm{NO}_{2}$.

\section{Modelled $\mathrm{NO}_{2}$ measurements from APMoSPHERE}

Modelled $\mathrm{NO}_{2}$ was derived from the European Union (EU)funded APMoSPHERE (Air Pollution Modelling for Support to Policy on Health and Environmental Risks in Europe). $\mathrm{NO}_{2}$ has been widely used as a marker for traffic-related air pollution. As part of APMoSPHERE $1 \mathrm{~km}$ resolution emission maps of several pollutants, including $\mathrm{NO}_{2}$, were developed for the then member states (EU15). Estimates were obtained by disaggregating national emissions estimates, categorised by sources of air pollution (SNAP categories), to the $1 \mathrm{~km}$ level on the basis of relevant proxies (eg, population density, road distribution, land cover). ${ }^{11}$ Modelling of $\mathrm{NO}_{2}$ concentrations was then done using focal sum techniques, in a geographical information system, to

Table 2 Ratio of mean annoyance scores from negative binomial regression

\begin{tabular}{|c|c|c|c|}
\hline & Crude & Adjusted by centre & Adjusted* \\
\hline & $\begin{array}{l}\text { Ratio of mean score } \\
(95 \% \mathrm{CI})\end{array}$ & $\begin{array}{l}\text { Ratio of mean score } \\
(95 \% \mathrm{Cl})\end{array}$ & $\begin{array}{l}\text { Ratio of mean score } \\
(95 \% \text { CI })\end{array}$ \\
\hline $\mathrm{NO}_{2}$ increase per $10 \mu \mathrm{g} \cdot \mathrm{m}^{-3} \uparrow$ & $1.29(1.25$ to 1.33$)$ & $1.27(1.21$ to 1.35$)$ & $1.26(1.19$ to 1.34$)$ \\
\hline \multirow[t]{3}{*}{$\mathrm{NO}_{2}$ in quartiles $t$} & $1.58(1.42$ to 1.76$)$ & 1.38 (1.21 to 1.58$)$ & $1.38(1.20$ to 1.60$)$ \\
\hline & $2.06(1.85$ to 2.29$)$ & $1.60(1.40$ to 1.84$)$ & $1.53(1.30$ to 1.78$)$ \\
\hline & $2.53(2.27$ to 2.81$)$ & $1.84(1.58$ to 2.15$)$ & 1.85 (1.55 to 2.19$)$ \\
\hline $\mathrm{NO}_{2}>27 \mu \mathrm{g} \cdot \mathrm{m}^{-3} \S$ & 1.78 (1.65 to 1.91$)$ & $1.32(1.20$ to 1.45$)$ & $1.29(1.16$ to 1.44$)$ \\
\hline
\end{tabular}

\footnotetext{
$\mathrm{NO}_{2}$, nitrogen dioxide.

${ }^{*}$ Sex, socioeconomic status, night shortness of breath, chronic phlegm, rhinitis, smoking, passive smoking, centre.

†Continuous.

\$Categorical, the reference is the lowest quartile.

$\S$ Dichotomous, below and above the median for measured plus modelled home outdoor $\mathrm{NO}_{2}$ levels.
} 
relate emissions within concentric zones around each monitoring site to the monitored concentrations. Models were developed using monitoring data from 714 background sites for 2001, drawn from the EU Airbase database. ${ }^{11}$ Validation was conducted by comparing predictions with observations for a separate set of 228 sites $\left(r^{2}=0.60\right)$.

When modelled $\mathrm{NO}_{2}$ estimates could not be provided, home outdoor measurements were used if available. That was the case for three cities that were/are not in the European Community (Reykjavik, Tartu and Basel, resulting in 207 subjects), for the subjects in Umeå who did not live in the city centre and were not geocoded for local reasons (117 subjects) and for some cases in the United Kingdom (25 subjects) and Spain (five subjects) for whom the address was not clear or was missing.

\section{Home outdoor $\mathrm{NO}_{2}$ measurements}

Measurements of $\mathrm{NO}_{2}$ as a marker for local tail pipe emissions were made at the homes of a subset of participants. At this individual level, outdoor (at the kitchen, or bedroom when kitchen was not available, window) and kitchen indoor $\mathrm{NO}_{2}$ concentrations were collected during a 14-day period in 16 centres during 2001, involving approximately 2050 households of subjects who did not move house during the follow-up. After approximately 6 months this procedure was repeated in $40 \%$ of the households. Values below limits of detection were set at half the detection limit $\left(0.34 \mu \mathrm{g} \cdot \mathrm{m}^{-3}\right)$ and values above 150 (maximum 180) $\mu \mathrm{g} \cdot \mathrm{m}^{-3}$ were set to $150 \mu \mathrm{g} \cdot \mathrm{m}^{-3}$. The passive samplers (Passam AG, Switzerland) were analysed in a central laboratory. For subjects with two measurements the mean of the two was calculated. Home outdoor $\mathrm{NO}_{2}$ measurements were used in this analysis when modelled $\mathrm{NO}_{2}$ measurements were not available.

\section{Statistical analysis}

Negative binomial regression was used to assess the association between annoyance and $\mathrm{NO}_{2}$. The multivariate model used was the same as that previously applied to analyse annoyance for this population. ${ }^{4}$ The variables included in the original model were sex, socioeconomic status, night shortness of breath, chronic phlegm, rhinitis, smoking status, exposure to environmental tobacco smoke and self-reported car and heavy vehicle traffic. Self-reported traffic was not, however, included in the model used here, as traffic is closely related to $\mathrm{NO}_{2}$ (and data on road traffic emissions are employed in the APMoSPHERE models). Annoyance and the other variables associated with it in the multivariate model were tested to see if subjects with $\mathrm{NO}_{2}$ measurements were different from those without measurements from the ECRHSII population. The WilcoxonMann-Whitney test was used for the annoyance score and the $\chi^{2}$ test for categorical variables. $\mathrm{NO}_{2}$ was analysed as a continuous variable, in quartiles and dichotomously (below and above the median). The results are expressed as ratios of the mean annoyance scores. Effect estimates were derived for each centre and area and heterogeneity across cities was examined by using standard methods for random effects meta-analysis. To help measure how well the estimates capture the variability of the annoyance score, we used the pseudo $\mathrm{R}^{2}$ given by the software, which is analogous to the $\mathrm{R}^{2}$ of the ordinary logistic regressions. The pseudo $R^{2}$ presented here was the inverse of the likelihood of the full model over the likelihood of the model including only the constant. The analysis was made using Stata 8 (Stata Corp, College Station, Texas, USA). The criterion for statistical significance was set at a $\mathrm{p}$ value of less than 0.05 .

\section{RESULTS}

Central medians of $\mathrm{NO}_{2}$ levels varied from $9.75 \mu \mathrm{g} \cdot \mathrm{m}^{-3}$ in Umeå (Sweden) to $57.32 \mu \mathrm{g} \cdot \mathrm{m}^{-3}$ in Barcelona (Spain). In general, northern centres had lower levels of $\mathrm{NO}_{2}$. In table 1, centres are ordered from north to south and data show the distribution of $\mathrm{NO}_{2}$ home outdoor level means per centre.

The distribution of annoyance per centre is reported in table 1 and the means ranked from 0.7 in Reykjavik (Iceland) to 4.38 in Huelva (Spain). The percentage of subjects highly annoyed (6 or more on the scale) varied from one in Reykjavik to 40 in Huelva. A north to south trend in reported annoyance was observed.

The association between $\mathrm{NO}_{2}$ and annoyance was positive and significant, disregarding the $\mathrm{NO}_{2}$ categorisation or the level of adjustment. When categorising the $\mathrm{NO}_{2}$, the estimates increased in accordance with $\mathrm{NO}_{2}$ quartiles (table 2).
Figure 1 Adjusted ratios of mean annoyance score (RMS) comparing the effect of nitrogen dioxide $\left(\mathrm{NO}_{2}\right)$ per centre.

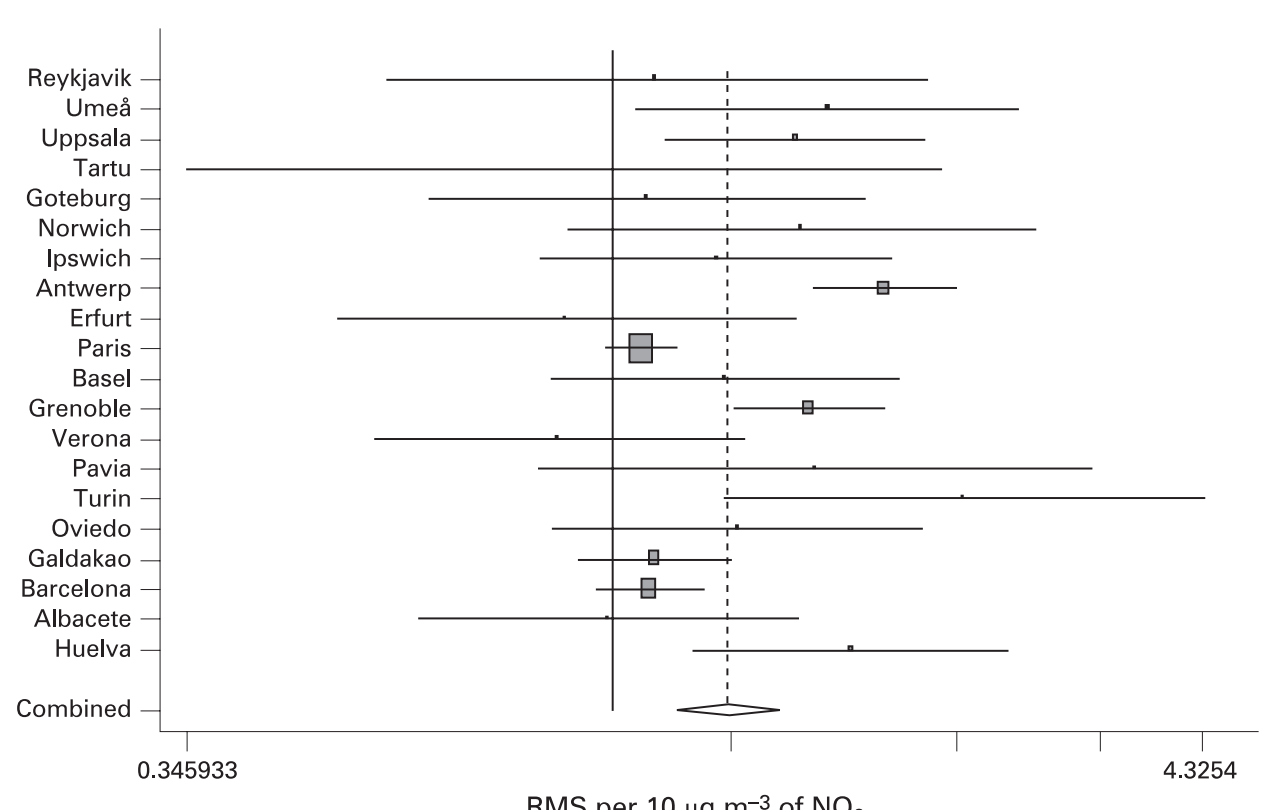

RMS per $10 \mu \mathrm{g} \cdot \mathrm{m}^{-3}$ of $\mathrm{NO}_{2}$ 
Table 3 Ratio of mean annoyance scores from negative binomial regression by each centre

\begin{tabular}{|c|c|c|c|c|}
\hline & \multicolumn{2}{|l|}{ Crude* } & \multicolumn{2}{|l|}{ Adjusted $^{* * *} \dagger$} \\
\hline & $\begin{array}{l}\text { Ratio of mean score } \\
(95 \% \mathrm{CI})\end{array}$ & $\mathbf{R}^{2}+$ & $\begin{array}{l}\text { Ratio of mean score } \\
(95 \% \mathrm{CI})\end{array}$ & $\mathbf{R}^{2}+$ \\
\hline Reykjavik & $1.23(0.66$ to 2.29$)$ & 0.003 & $1.11(0.57$ to 2.18$)$ & 0.062 \\
\hline Umeå & $1.73(1.14 \text { to } 2.64)^{*}$ & 0.007 & $1.70(1.06 \text { to } 2.73)^{*}$ & 0.026 \\
\hline Uppsala & $1.57(1.16 \text { to } 2.13)^{*}$ & 0.007 & $1.57(1.14 \text { to } 2.17)^{*}$ & 0.027 \\
\hline Tartu & 1.27 (0.68 to 2.38$)$ & 0.004 & $0.88(0.35 \text { to } 2.25)^{* *}$ & 0.104 \\
\hline Goteburg & $1.14(0.67$ to 1.94$)$ & 0.000 & $1.09(0.63$ to 1.88$)$ & 0.015 \\
\hline Norwich & $1.78(1.11 \text { to } 2.84)^{*}$ & 0.007 & $1.60(0.89$ to 2.85$)$ & 0.032 \\
\hline Ipswich & 1.25 (0.85 to 1.84$)$ & 0.001 & $1.29(0.83$ to 1.99$)$ & 0.006 \\
\hline Antwerp & $1.89(1.61 \text { to } 2.23)^{*}$ & 0.024 & $1.96(1.63 \text { to } 2.35)^{*}$ & 0.035 \\
\hline Erfurt & 0.88 (0.56 to 1.38$)$ & 0.001 & $0.89(0.50 \text { to } 1.58)^{* *}$ & 0.037 \\
\hline Paris & $1.08(0.99 \text { to } 1.18)^{* *}$ & 0.002 & $1.08(0.98$ to 1.18$)$ & 0.014 \\
\hline Basel & $1.16(0.83$ to 1.60$)$ & 0.002 & $1.32(0.86$ to 2.03$)$ & 0.020 \\
\hline Grenoble & $1.74(1.45 \text { to } 2.08)^{*}$ & 0.021 & $1.62(1.35 \text { to } 1.96)^{*}$ & 0.030 \\
\hline Verona & $1.03(0.69$ to 1.55$)$ & 0.000 & $0.87(0.55 \text { to } 1.39)^{* *}$ & 0.016 \\
\hline Pavia & $1.60(0.93 \text { to } 2.75)^{* *}$ & 0.004 & 1.65 (0.83 to 3.28$)$ & 0.024 \\
\hline Torino & $1.55(0.83$ to 2.88$)$ & 0.005 & $2.38(1.31 \text { to } 4.33)^{*}$ & 0.108 \\
\hline Oviedo & $1.19(0.80$ to 1.76$)$ & 0.001 & $1.37(0.86$ to 2.16$)$ & 0.023 \\
\hline Galdakao & $1.16(0.99 \text { to } 1.35)^{* *}$ & 0.002 & $1.11(0.91$ to 1.34$)$ & 0.007 \\
\hline Barcelona & $1.11(0.98$ to 1.26$)$ & 0.002 & $1.10(0.96$ to 1.26$)$ & 0.016 \\
\hline Albacete & $1.07(0.70$ to 1.62$)$ & 0.000 & $0.99(0.61 \text { to } 1.59)^{* *}$ & 0.015 \\
\hline Huelva & $1.58(1.16 \text { to } 2.15)^{*}$ & 0.008 & $1.80(1.23 \text { to } 2.65)^{*}$ & 0.036 \\
\hline All fixed & $1.26(1.19 \text { to } 1.32)^{*}$ & 0.013 & $1.24(1.18 \text { to } 1.32)^{*}$ & 0.034 \\
\hline All random & $1.32(1.18 \text { to } 1.49)^{*}$ & NA & $1.33(1.17 \text { to } 1.52)^{*}$ & NA \\
\hline
\end{tabular}

${ }^{*} \mathrm{p}<0.05 ;{ }^{* *} \mathrm{p}<0.10 ;{ }^{* * *} \mathrm{p}<0.001$ for heterogeneity.

$\uparrow$ Sex, socioeconomic status, night shortness of breath, chronic phlegm, rhinitis, smoking, passive smoking, centre.

$\$$ Pseudo $\mathrm{R}^{2}$ of the whole model.

Figure 1 shows the centre-specific adjusted estimates. The $p$ value for heterogeneity was below 0.001. Table 3 shows the specific crude and adjusted estimates and the pseudo R2 of each model for each centre. For the adjusted analysis the association was positive and significant in Umeå, Uppsala, Antwerp, Grenoble, Torino and Huelva; positive but not significant in Reykjavik, Goteborg, Norwich, Ipswich, Paris, Basel, Pavia, Oviedo, Galdakao and Barcelona and negative but not significant in Tartu, Erfurt, Verona and Albacete. The general pseudo $R^{2}$ for the crude model was 0.13 and the pseudo $R^{2}$ distribution within cities varied from 0 to 0.024 for the crude model and from 0.006 to 0.104 in the adjusted model.

The association between annoyance and $\mathrm{NO}_{2}$ stratified by gender and by respiratory symptoms is presented in table 4. All the subgroups showed a similar association and in all cases the pseudo $\mathrm{R}^{2}$ was low, approximately 0.03 . Stratifying by atopy gave similar results; the pseudo $R^{2}$ being 0.04 in atopic and 0.03 in non-atopic individuals.

\section{DISCUSSION}

Annoyance caused by air pollution was associated with home outdoor $\mathrm{NO}_{2}$ measurements; nevertheless this association was different among cities. The estimates were very weak even in the centres with the strongest associations and were even negative in some cities. No clear geographical pattern could be observed. No specific subgroup of subjects who could better predict $\mathrm{NO}_{2}$ with annoyance was found.

One of the strengths of this study was the large number of participating cities across Europe, allowing us to compare the heterogeneity of associations between $\mathrm{NO}_{2}$ and annoyance across different European countries. Another advantage was that it included measurements of $\mathrm{NO}_{2}$ estimated (or measured) at the place of residence, thus allowing the association with annoyance to be analysed at the individual level. Although $\mathrm{NO}_{2}$ per se may not cause annoyance, it is a widely used surrogate of traffic-related pollutants and thus is expected to correlate with traffic emissions that may be more easily identified as a bad smell. For annoyance caused by air pollution, to our knowledge, only three previous studies have used individual-level air pollution concentrations. ${ }^{35} 7$

An issue that has been raised previously about the association between annoyance caused by air pollution and air pollution is that the question itself has limitations in its phrasing. On the one hand, it concerns annoyance caused by outdoor air

Table 4 Ratio of mean annoyance scores from negative binomial regression stratified

\begin{tabular}{|c|c|c|c|c|c|c|c|c|c|c|}
\hline & \multicolumn{2}{|l|}{ All } & \multicolumn{2}{|l|}{ For women } & \multicolumn{2}{|l|}{ For men } & \multicolumn{2}{|c|}{$\begin{array}{l}\text { Without any respiratory } \\
\text { symptoms }\end{array}$} & \multicolumn{2}{|l|}{$\begin{array}{l}\text { With any respiratory } \\
\text { symptom }\end{array}$} \\
\hline & $\begin{array}{l}\text { Ratio of mean score } \\
(95 \% \mathrm{Cl})\end{array}$ & $\mathbf{R}^{2} \dagger$ & $\begin{array}{l}\text { Ratio of mean score } \\
(95 \% \mathrm{Cl})\end{array}$ & $\mathbf{R}^{2} \dagger$ & $\begin{array}{l}\text { Ratio of mean score } \\
(95 \% \mathrm{CI})\end{array}$ & $R^{2} \dagger$ & $\begin{array}{l}\text { Ratio of mean score } \\
(95 \% \mathrm{Cl})\end{array}$ & $\mathbf{R}^{2} \uparrow$ & $\begin{array}{l}\text { Ratio of mean score } \\
(95 \% \mathrm{Cl})\end{array}$ & $R^{2} \dagger$ \\
\hline Crude & $1.29(1.25$ to 1.33$)$ & 0.01 & $1.28(1.23$ to 1.34$)$ & 0.01 & 1.30 (1.24 to 1.37$)$ & 0.01 & $1.30(1.22$ to 1.38$)$ & 0.01 & $1.28(1.23$ to 1.33$)$ & 0.01 \\
\hline Adjusted per centre & $\mathrm{e} 1.27$ (1.21 to 1.35$)$ & 0.03 & $1.32(1.23$ to 1.42$)$ & 0.03 & $1.20(1.11$ to 1.30$)$ & 0.03 & $1.38(1.24$ to 1.53$)$ & 0.03 & $1.23(1.15$ to 1.31$)$ & 0.03 \\
\hline Fully adjusted* & $1.26(1.19$ to 1.34$)$ & 0.03 & $1.31(1.20$ to 1.42$)$ & 0.04 & $1.22(1.11$ to 1.33$)$ & 0.04 & $1.41(1.25$ to 1.58$)$ & 0.03 & $1.21(1.13$ to 1.29$)$ & 0.03 \\
\hline
\end{tabular}

\footnotetext{
${ }^{*}$ Sex, socioeconomic status, night shortness of breath, chronic phlegm, rhinitis, smoking, passive smoking, centre.
}

$\uparrow$ Pseudo $\mathrm{R}^{2}$ of the whole model. 
pollution while indoors; this is likely to be influenced by the frequency with which the individuals open their windows, as well as the proportion of time spent indoors and general ventilation conditions. Assuming that individuals in colder (northern) countries are less likely to open their windows, we would expect weaker associations in northern countries. This was, however, not the case: the association between annoyance and air pollution showed no clear geographical pattern. The estimates, as well as the pseudo $\mathrm{R}^{2}$, for each centre were instead very heterogeneous. It is also important to note that the inclusion in the multivariate model of the variable "Do you sleep with the window open in winter?", as well as the variable assessing the frequency of such events, did not alter the estimate of the association between annoyance and $\mathrm{NO}_{2}$. In stratified analyses, the estimate was similar in subjects sleeping with the window open to those who do not, and even tended to be slightly smaller in the former. To sleep with the window open was associated with annoyance only in the crude model; once centre was added into the model, the association disappeared. The season of the interview was not associated with annoyance, nor with the association between annoyance and $\mathrm{NO}_{2}$.

Another weakness of this study is that the subsample for whom $\mathrm{NO}_{2}$ values were available was not the same as that without them. Subjects with $\mathrm{NO}_{2}$ concentrations available tended to be more annoyed by air pollution. They also included more women and more people in formal employment (as opposed to others such as housewives or students), had more rhinitis, were less likely to be current smokers and reported more traffic than the subjects without $\mathrm{NO}_{2}$ values. The reasons for these discrepancies are not clear, because a high proportion $(70 \%)$ of participants in the random sample of ECRHSII had $\mathrm{NO}_{2}$ values. The main determinant of exposure estimation was the ability to geocode the address, which in principle has nothing to do directly with the personal characteristics of the subjects. There were, however, possible biases in Umeå and Goteborg, where only participants living in the city centre could be geocoded.

Most of the studies investigating the association between annoyance and air pollution have found a correlation between both, using central, personal modelled and/or individual concentrations of pollutants. They have also usually concluded that personal characteristics also play a big role in the rating of annoyance. To our knowledge, however, no previous studies have compared associations between countries.

Forsberg et al, ${ }^{2}$ for example, showed an association between annoyance caused by air pollution and central $\mathrm{NO}_{2}$ concentrations. The correlation coefficient between the percentage of subjects reporting annoyance per city or town and the 6-month average $\mathrm{NO}_{2}$ was approximately 0.60. They found a better correlation for subjects living in urban areas than for those living in residential areas. ${ }^{2}$ Williams and $\mathrm{Bird}^{6}$ showed that the perception of air pollution was not a reliable indicator of the actual levels when using the measurements from the nearest monitoring station in Greater London. They did not compare among different cities but they showed that inside the same city, subjects living in urban areas were more disturbed than subjects living in suburban areas. Klaeboe et al found an association between environmental annoyance and a 3 months mean of modelled $\mathrm{NO}_{2}$ in Oslo. Subjects tended to have more complaints or higher levels of annoyance when the levels of $\mathrm{NO}_{2}$ were higher. ${ }^{7}$ Oglesby et al found a significant association between high annoyance caused by air pollution and estimated home outdoor $\mathrm{NO}_{2}$ in eight Swiss cities. The association was not, however, significant when they used the annoyance score. The crude correlation between annoyance score and estimated home outdoor $\mathrm{NO}_{2}$ was $\mathrm{r}=0.36$ and explained $7.5 \%$ of the annoyance variance. They also suggested that subjects could rate annoyance differently from one area to another within the same country. ${ }^{3}$ Rotko et $a l^{5}$ found a very high correlation between annoyance caused by air pollution in traffic and the home outdoor $\mathrm{NO}_{2}$ concentration when aggregating the results by city $(r=0.99)$. When assessing the association individually, it was significant but the crude model only explained $13 \%$ of the annoyance variance. They had individual level $\mathrm{NO}_{2}$ measurements for four cities in Europe but they did not compare between the cities. ${ }^{5}$ In a previous publication, ${ }^{4}$ we assessed the association between annoyance caused by air pollution and air pollution characterised at one central monitor instead of the residential location. We found a moderate association that was heterogeneous among centres. ${ }^{4}$ Now, in this study we show how the relation between annoyance and air pollution also differed by geographical areas even using individual determinations. The association is heterogeneous and the levels of $\mathrm{NO}_{2}$ explained very little of the annoyance variance at the individual level, as reported previously.

Even if home outdoor $\mathrm{NO}_{2}$ and annoyance caused by air pollution are associated, we do not recommend the use of annoyance as a surrogate for personal exposure to traffic-related air pollution. The general pseudo $\mathrm{R}^{2}$ for the crude model was low and the pseudo $\mathrm{R}^{2}$ distribution within cities varied. Only a small part of the $\mathrm{NO}_{2}$ variation can thus be predicted on the basis of annoyance. The correlation is only partly explained by the levels of the pollutants and the personal characteristics. We were not able to identify a subgroup of subjects who would better predict the $\mathrm{NO}_{2}$ level in comparison with the total population, although we selected women and/or subjects with respiratory symptoms in whom one could plausibly argue that those subjects tended to be more annoyed by air pollution. ${ }^{4}$ Another reason why we do not recommend the use of annoyance as an air pollution indicator is its heterogeneity. The estimates varied from negative to positive association without any discernable geographical pattern. To interpret a pooled estimate would be incorrect.

The fact that the association between annoyance and $\mathrm{NO}_{2}$ varies from city to city suggests a sociocultural influence. The importance of personal, social and cultural factors in influencing risk perception has long been well established. ${ }^{12}$ Bickerstaff $^{13}$ explained how social and cultural factors could influence the perception of air pollution. The main conclusion was probably that the perception of risk takes into account numerous factors including social, political and cultural ones and that there is not a set of variables that could predict the risk perception at a group level. Olofsson and Ohman ${ }^{14}$ showed that personal characteristics, including political affiliation or education, could predict environmental concern but the addition of general beliefs, such as beliefs about science or a view of nature, increased predictability. They also showed that the individual factors related to environmental concern were not the same and did not have the same predictive power between the two geographical areas they studied (north America versus Scandinavia). Dietz et $a l^{15}$ investigated whether individual characteristics and/or beliefs could explain their environmental willingness to act. They found no clear association and that environmental participation was not predictable. Annoyance is thus subjective, and not all the annoyance can be explained by measurable variables. Subjectivity does not, however, take away its importance, as it reflects the subjects' feelings. Also it has 


\section{What this paper adds}

- It has been suggested that annoyance caused by air pollution reported through a questionnaire could be used as an indicator of exposure to air pollution. Several studies have shown a moderate to good association between central levels of air pollution. The objective of this study was to assess the association between reported annoyance caused by air pollution and home outdoor levels of $\mathrm{NO}_{2}$, a marker for trafficrelated pollution, in 20 cities from 10 countries and investigate the geographical homogeneity thereof.

- Annoyance caused by air pollution was associated with home outdoor $\mathrm{NO}_{2}$ measurements; nevertheless this association was heterogeneous among cities. No specific subgroup of subjects who could better predict $\mathrm{NO}_{2}$ with annoyance was found. Whereas this and other studies ultimately confirm that annoyance is not a valid maker of air pollution exposure, it is important in its own right as it integrates perception, feelings of security and health problems.

been suggested that annoyance per se could have health effects. Individuals are aware of health effects of air pollution and are concerned about it, even when the levels are in accordance with the guidelines. ${ }^{16}{ }^{17}$ Lercher et $a l^{8}$ found an association between annoyance and respiratory symptoms not explained by air pollution concentrations and suggested that the perception of polluted air could trigger annoyance and symptoms even when air pollution levels are below the guidelines. It has also been suggested that a negative impression of the general environment of the neighbourhood was associated with a lower health quality. ${ }^{18} 19$

Policy makers might take into account the annoyance caused by air pollution as a direct outcome of interest. Although this and other studies ultimately confirm that annoyance is not a valid maker of air pollution exposure, it is important in its own right as it integrates individual perception, feelings of security and health problems. It may also influence trust in government and the regulatory authorities. ${ }^{20}$ Its standardised measurement is simple and it could easily be added to environmental monitoring and health tracking surveys.

Funding: The coordination of ECRHS II was supported by the European Commission, as part of their Quality of Life programme. The following bodies funded the local studies in ECRHS II included in this paper: Albacete: Fondo de Investigaciones Sanitarias (FIS) (grant code 97/0035-01, 99/0034-01 and 99/0034-02). Hospital Universitario de Albacete, Consejería de Sanidad; Antwerp: FWO (Fund for Scientific Research), Flanders, Belgium (grant code G.0402.00), University of Antwerp, Flemish Health Ministry; Barcelona: SEPAR, Public Health Service (grant code R01 HL6263301), Fondo de Investigaciones Santarias (FIS) (grant code 97/0035-01, 99/0034-01 and 99/0034-02) CIRIT (grant code 1999SGR 00241) "Instituto de Salud Carlos III" Red de Centros RCESP, C03/09 and Red RESPIRA, C03/011; Basel: Swiss National Science Foundation, Swiss Federal Office for Education \& Science, Swiss National Accident Insurance Fund (SUVA); Bergen: Norwegian Research Council, Norwegian Asthma \& Allergy Association (NAAF), Glaxo Wellcome AS, Norway Research Fund; Bordeaux: Institut Pneumologique d'Aquitaine; Erfurt: GSF-National Research Centre for Environment \& Health, Deutsche Forschungsgemeinschaft (DFG) (grant code FR 1526/ 1-1); Galdakao: Basque Health Dept; Göteborg: Swedish Heart Lung Foundation, Swedish Foundation for Health Care Sciences \& Allergy Research, Swedish Asthma \& Allergy Foundation, Swedish Cancer \& Allergy Foundation; Grenoble: Programme Hospitalier de Recherche Clinique-DRC de Grenoble 2000 no 2610, Ministry of Health, Direction de la Recherche Clinique, Ministère de I'Emploi et de la Solidarité, Direction Générale de la Santé, CHU de Grenoble, Comite des Maladies Respiratoires de l'Isère; Hamburg: GSF-National Research Centre for Environment \& Health, Deutsche Forschungsgemeinschaft (DFG) (grant code MA 711/4-1); Ipswich and Norwich: National Asthma Campaign (UK); Huelva: Fondo de Investigaciones Sanitarias (FIS) (grant code 97/0035-01, 99/0034-01 and 99/0034-02); Montpellier: Programme Hospitalier de Recherche Clinique-DRC de Grenoble 2000 no 2610, Ministry of Health, Direction de la Recherche Clinique, CHU de Grenoble, Ministère de l'Emploi et de la Solidarité, Direction Générale de la Santé, Aventis (France), Direction Régionale des Affaires Sanitaires et Sociales Languedoc-Roussillon; Oviedo: Fondo de Investigaciones Santarias (FIS) (grant code 97/0035-01, 99/0034-01 and 99/0034-02); Paris: Ministère de l'Emploi et de la Solidarité, Direction Générale de la Santé, UCB-Pharma (France), Aventis (France), Glaxo France, Programme Hospitalier de Recherche Clinique-DRC de Grenoble 2000 no 2610, Ministry of Health, Direction de la Recherche Clinique, CHU de Grenoble; Pavia: Glaxo-SmithKline Italy, Italian Ministry of University and Scientific and Technological Research (MURST), Local University Funding for research 1998 \& 1999 (Pavia, Italy): Reykjavik: Icelandic Research Council, Icelandic University Hospital Fund Tartu: Estonian Science Foundation; Turin: ASL 4 Regione Piemonte (Italy), AO CTO/ ICORMA Regione Piemonte (Italy), Ministero dell'Università e della Ricerca Scientifica (Italy), Glaxo Wellcome spa (Verona, Italy); Umeå: Swedish Heart Lung Foundation, Swedish Foundation for Health Care Sciences \& Allergy Research, Swedish Asthma \& Allergy Foundation, Swedish Cancer \& Allergy Foundation; Uppsala: Swedish Heart Lung Foundation, Swedish Foundation for Health Care Sciences \& Allergy Research, Swedish Asthma \& Allergy Foundation, Swedish Cancer \& Allergy Foundation; Verona: University of Verona; Italian Ministry of University and Scientific and Technological Research (MURST); Glaxo-SmithKline Italy. The APMoSPHERE study (EVK2-200200577) was a multi-centre project, funded under the EU Fifth Framework Programme as part of the Global Monitoring for Environment and Security (GMES) initiative. It was led by Prof David Briggs (Imperial College London) and co-principal investigators were Dr Asbjorn Aaheim (Centre for International Climate and Environmental Research, Oslo), Dr Gerard Hoek (Utrecht University), Dr Mike Petrakis (National Observatory of Athens) and Dr Gavin Shaddick (University of Bath).

Competing interests: None.

Ethics approval: Ethics approval was obtained for each centre from the appropriate institutional or regional ethics committee.

\section{REFERENCES}

1. Nuckols JR, Ward MH, Jarup L. Using geographic information systems for exposure assessment in environmental epidemiology studies. Environ Health Perspect 2004;112:1007-15.

2. Forsberg B, Stjernberg N, Wall S. People can detect poor air quality well below guideline concentrations: a prevalence study of annoyance reactions and air pollution from traffic. Occup Environ Med 1997:54:44-8.

3. Oglesby L, Kunzli N, Monn C, et al. Validity of annoyance scores for estimation of long term air pollution exposure in epidemiologic studies: the Swiss Study on Air Pollution and Lung Diseases in Adults (SAPALDIA). Am J Epidemiol 2000;152:75-83.

4. Jacquemin B, Sunyer J, Forsberg B, et al. Annoyance due to air pollution in Europe. Int J Epidemiol 2007;4:809-20.

5. Rotko T, Oglesby L, Kunzli N, et al. Determinants of perceived air pollution annoyance and association between annoyance scores and air pollution $\left(\mathrm{PM}_{2.5}, \mathrm{NO}_{2}\right)$ concentrations in the European EXPOLIS study. Atmosph Environ 2002;36:4593-602.

6. Williams ID, Bird A. Public perceptions of air quality and quality of life in urban and suburban areas of London. J Environ Monit 2003:5:253-9.

7. Klaeboe R, Kolbenstvedt M, Clench-Aas J, et al. Oslo traffic study-part 1: an integrated approach to assess the combined effects of noise and air pollution on annoyance. Atmosphc Environ 2000;34:4727-36.

8. Lercher $\mathbf{P}$, Schmitzberger R, Kofler W. Perceived traffic air-pollution, associated behavior and health in an alpine area. Sci Tot Environ 1995;169:71-4.

9. The European Community Respiratory Health Survey II. Eur Respir J 2002;20:1071-9.

10. Burney PG, Luczynska C, Chinn S, et al. The European Community Respiratory Health Survey. Eur Respir J 1994;7:954-60.

11. APMoSPHERE Air Pollution Modelling for Support to Policy on Health and Environmental Risk in Europe. http://www.apmosphere.org (accessed Nov 2007).

12. Slovic P. Perception of risk. Science 1987;236:280-5.

13. Bickerstaff $\mathbf{K}$. Risk perception research: socio-cultural perspectives on the public experience of air pollution. Environ Int 2004;30:827-40.

14. Olofsson A, Ohman S. General beliefs and environmental concern-Transatlantic comparisons. Environ Behav 2006;38:768-90.

15. Dietz T, Stern PC, Guagnano GA. Social structural and social psychological bases of environmental concern. Environ Behav 1998;30:450-71.

16. Elliott SJ, Cole DC, Krueger $\mathrm{P}$, et al. The power of perception: health risk attributed to air pollution in an urban industrial neighbourhood. Risk Anal 1999;19:621-34.

17. Evans GW, Colome SD, Shearer DF. Psychological reactions to air pollution. Environ Res 1988;45:1-15.

18. Bowling A, Barber J, Morris R, et al. Do perceptions of neighbourhood environment influence health? Baseline findings from a British survey of aging. J Epidemiol Community Health 2006;60:476-83.

19. Steptoe A, Feldman PJ. Neighborhood problems as sources of chronic stress: development of a measure of neighborhood problems, and associations with socioeconomic status and health. Ann Behav Med 2001;23:177-85.

20. Slovic P. Perceived risk, trust, and democracy. Risk Anal 1993;13:675-82. 